\title{
Hospice Landscape Report
}

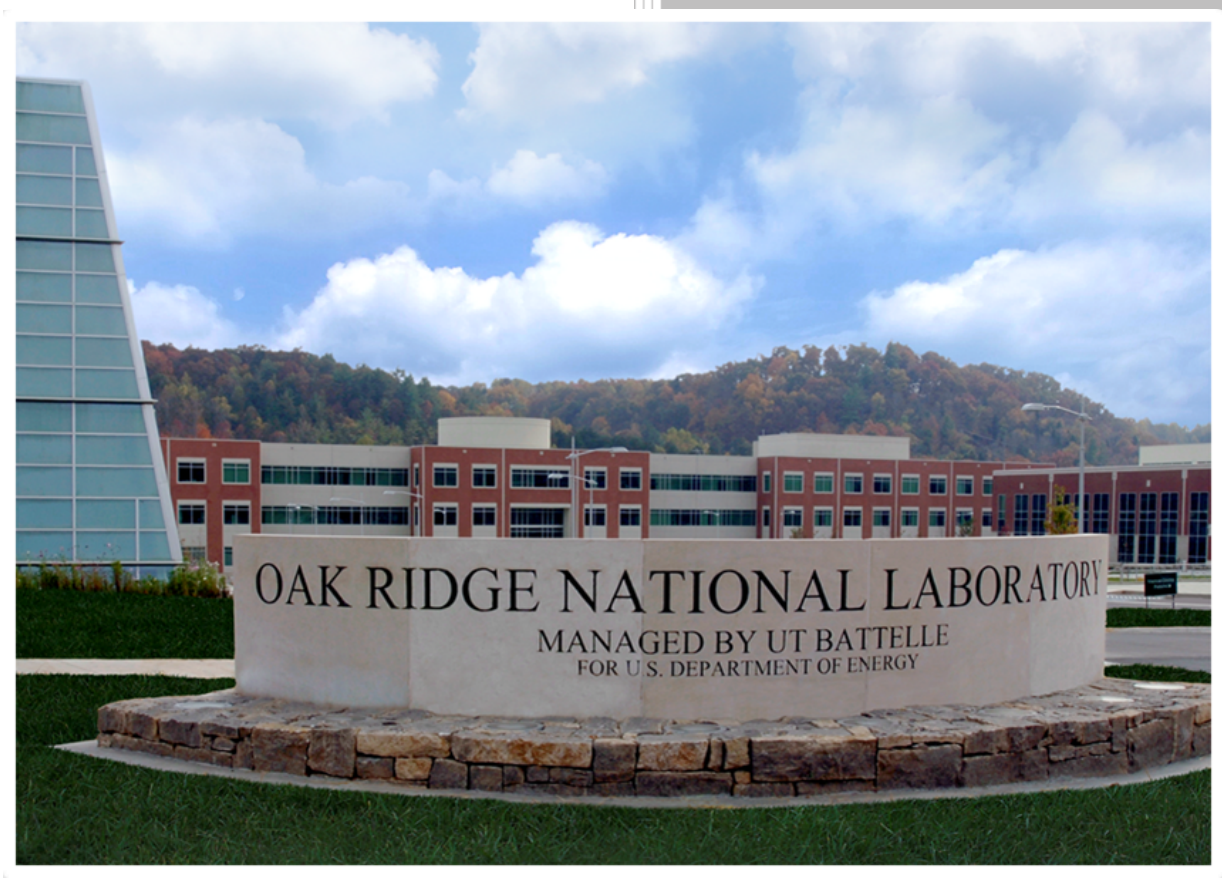

This report was prepared as an account of work sponsored by an agency of the United States Government. Neither the United States Government nor any agency thereof, nor any of their employees, makes any warranty, express or implied, or assumes any legal liability or responsibility for the accuracy, completeness, or usefulness of any information, apparatus, product, or process disclosed, or represents that its use would not infringe privately owned rights. Reference herein to any specific commercial product, process, or service by trade name, trademark, manufacturer, or otherwise, does not necessarily constitute or imply its endorsement, recommendation, or favoring by the United States Government or any agency thereof. The views and opinions of authors expressed herein do not necessarily state or reflect those of the United States Government or any agency thereof.

\author{
Edmon Begoli \\ Kathryn Knight \\ Daniel Redmon \\ Ashley Rice \\ Laurie Varma
}

December 2021 
Computational Sciences and Engineering Division Computer Science and Mathematics Division Cyber Resilience and Intelligence Division Information Technology Services Division

\title{
HOSPICE LANDSCAPE REPORT
}

\author{
Edmon Begoli \\ Kathryn Knight \\ Daniel Redmon \\ Ashley Rice \\ Laurie Varma
}

ORNL Principal Investigator Edmon Begoli

ORNL Program Manager Jeremy Cohen

ORNL Project Manager Daniel Redmon

Date Published: September 2021

Revised: December 2021

Prepared for

John Brunolli and Rick Todd

Centers for Medicare and Medicaid Services

Division of Medicare Advantage Audits

Prepared by

OAK RIDGE NATIONAL LABORATORY

Oak Ridge, TN 37831-6283

managed by

UT-BATTELLE, LLC

for the

US DEPARTMENT OF ENERGY

under contract DE-AC05-00OR22725 


\section{CONTENTS}

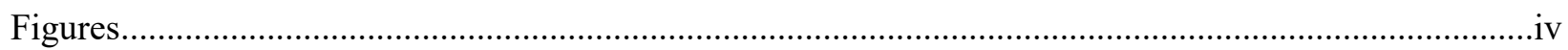

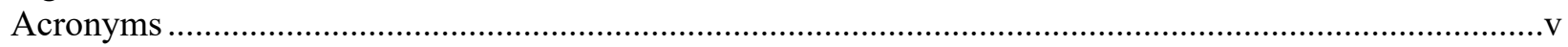

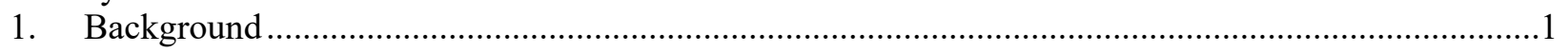

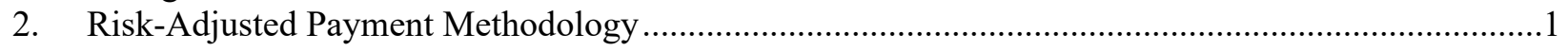

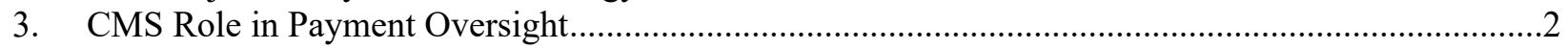

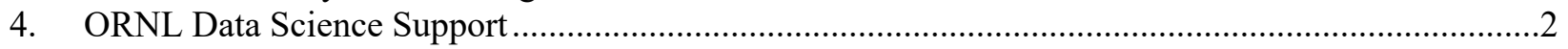

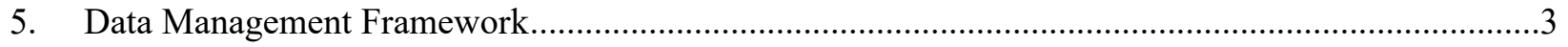

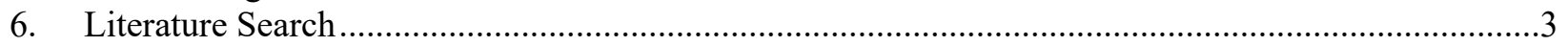

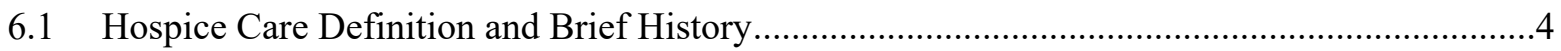

6.2 Identifying Fraud Schemes in Hospice Care ......................................................................

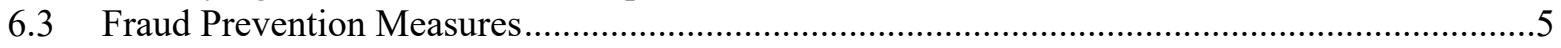

6.4 Impact of Hospice Fraud Beyond Medicare Overpayments ...................................................5

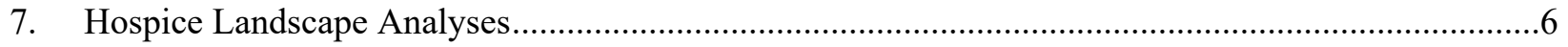

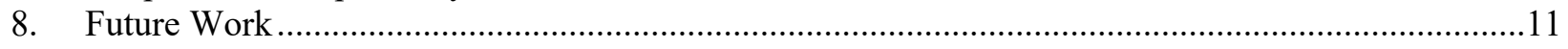

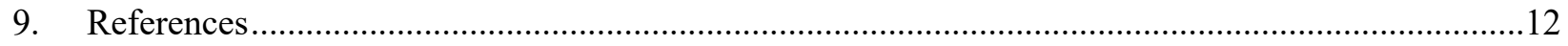




\section{FIGURES}

Figure 1. Gender distribution of hospice patients, January 2015-June 2019.......................................

Figure 2. Geographical distribution of hospice patients, January 2015-June 2019................................

Figure 3. Diagnosis distribution of hospice patients, January 2015-June 2019.......................................8

Figure 4. MDC distribution of hospice patients, January 2015-June 2019...........................................

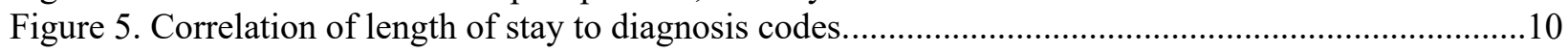

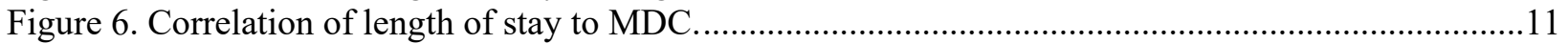

Hospice Landscape Report iv 


\section{ACRONYMS}

$\begin{array}{ll}\text { BBA of 1997 } & \text { Balanced Budget Act of 1997 } \\ \text { CHC } & \text { Continuous Home Care } \\ \text { CMS } & \text { Centers for Medicare and Medicaid Services } \\ \text { COPD } & \text { Chronic Obstructive Pulmonary Disease } \\ \text { CPI } & \text { Center for Program Integrity } \\ \text { EDS } & \text { Encounter Data System } \\ \text { ENCLSAS } & \text { Encounter Data Version of the RAPS Diagnosis Data } \\ \text { GIP } & \text { General Inpatient Care } \\ \text { HCC } & \text { hierarchical condition category } \\ \text { HHS } & \text { US Department of Health and Human Services } \\ \text { ICD } & \text { International Statistical Classification of Diseases and Related Health Problems } \\ \text { KDI } & \text { Knowledge Discovery Infrastructure } \\ \text { MAO } & \text { Medicare Advantage Organization } \\ \text { MDC } & \text { major diagnosis codes } \\ \text { MMA of 2003 } & \text { Medicare Prescription Drug and Modernization Act of 2003 } \\ \text { OIG } & \text { Office of the Inspector General } \\ \text { ORNL } & \text { Oak Ridge National Laboratory } \\ \text { RADV } & \text { Risk Adjustment Data Validation } \\ \text { RAPS } & \text { Risk Adjustment Payment System } \\ \text { RHC } & \text { Routine Home Care } \\ \text { SFTP } & \text { secure file transfer protocol } \\ \text { WFA } & \text { waste, fraud, and abuse }\end{array}$


ORNL/SPR-2021/2271

\section{BACKGROUND}

In 2018, 60 million Americans were enrolled in the Medicare program, 3.8 million of whom were new enrollees. Nearly $40 \%$ were participating in the Medicare Advantage program, and $74 \%$ were accessing medications through Part D. The care accessed the most by participants included ongoing, nonacute care such as health screenings, doctor visits, and immunizations, in addition to medications.

The Medicare and Medicaid programs grew from the July 1965 law creating "original" Medicare: Part A, which oversees hospital insurance, and Part B, which oversees personal and family medical insurance for those insured by the federal government, called "fee-for-service" Medicare. In 1972, the US Congress expanded Medicare to cover people aged 65 and older, people with disabilities, and people with end-stage renal disease requiring dialysis or a kidney transplant. Additional benefits such as drug coverage (as part of Medicare Part D) have been provided since Medicare was launched. Medicaid has also grown from a program offering health care services to people getting cash assistance from the federal government to include low-income families, pregnant women, people with disabilities, and people needing long-term care.

The Balanced Budget Act of 1997 (BBA of 1997) gave Medicare beneficiaries the option to receive their Medicare benefits through private health insurance plans, known as Medicare+Choice or Part C plans. Medicare Part C was developed as an alternative to "original" Medicare for eligible senior citizens and people with disabilities, with services under Parts A, B, and D usually included in Part C coverage. Subsequent passage of the Medicare Prescription Drug and Modernization Act of 2003 (MMA of 2003) changed the compensation and business practices for these private health insurance plans.

"Medicare+Choice" plans became known as Medicare Advantage plans while health care providers providing services under the plans became known as Medicare Advantage Organizations (MAOs).

\section{RISK-ADJUSTED PAYMENT METHODOLOGY}

Both the MMA of 2003 and the BBA of 1997 impacted MAOs, mandating that the monthly payments MAOs receive from the federal government be based on the health status of beneficiaries. (The same mandates were placed on private managed care organizations.) Under the risk-adjusted payment system, the Centers for Medicare and Medicaid Services (CMS) assigns a risk score to each beneficiary, primarily based on the individual's previous year health record and demographic information such as age and geographic location. The amount of reimbursement MAOs receive for services provided to a beneficiary is based on base rate (i.e., benchmark or plan's bid, whichever is lower); risk adjustment (i.e., base rate adjusted for the beneficiary's risk score); premiums charged to the beneficiary; and rebates provided to the MAO by CMS.

MAOs submit diagnostic data to CMS from beneficiary medical records to receive risk-adjusted payment. MAOs submitted diagnosis codes through Risk Adjustment Payment System (RAPS) and is being phased out for the Encounter Data System (EDS) starting in 2015. RAPS data consists of single, annually submitted diagnoses for each beneficiary. For each submission, the system collects health insurance claim number; provider type; service from and service through dates; and ICD-9-CM and ICD-10-CM and blended hierarchical condition category (HCC) codes (i.e., disease groups). EDS data consists of data elements from all dates of service for a beneficiary, providing information on utilization and cost of 
services for each beneficiary. Risk-adjusted payment is based on the CMS-HCC model, which uses disease groups associated with ICD codes; diagnoses from multiple sites of care; and type of care (i.e., community-based outpatient vs. long-term institutional) to determine payments.

\section{CMS ROLE IN PAYMENT OVERSIGHT}

The CMS, a federal agency within the US Department of Health and Human Services (HHS), administers the Medicare program and partners with state governments to administer Medicaid. In this role, CMS also oversees the Children's Health Insurance Program, the state and federal health insurance marketplace, and facilities providing long-term care (i.e., nursing homes) and end-of-life care (i.e., hospice agencies). CMS collects and analyzes usage and reporting data that aids in the administration of the Medicare and Medicaid programs and helps identify waste, fraud, and abuse (WFA) among health care providers. Part of the mission of the Center for Program Integrity (CPI), under the CMS, is to detect and combat WFA of the Medicare and Medicaid programs. CPI works to ensure accurate payments for services covered under their health care programs by performing medical reviews and audits and utilizes predictive analytics to seek out and identify potential WFA for deeper investigation. CMS has long noted unsupported diagnostic submissions for risk adjustment, citing it as the sole driver of improper payments.

Beginning in 2002, Risk Adjustment Data Validation (RADV), which provides postpayment validation of diagnoses submitted to CMS for risk adjustment purposes, has been implemented as the primary corrective action plan to reduce the Medicare Part $\mathrm{C}$ error rate. RADV identifies improper payments by identifying the difference in beneficiary-level payment due to a change in risk score based on medical record reviews. The corrected risk score is calculated based on diagnoses from medical records that plans submit to CMS for purposes of RADV. RAPS and Encounter submissions are used to calculate a beneficiary's risk score.

\section{ORNL DATA SCIENCE SUPPORT}

In July 2018, CMS requested assistance from Oak Ridge National Laboratory (ORNL) to provide expert data science support aimed at developing algorithms for data mining of medical data for operational and payment purposes. The project is intended to be exploratory: work is aimed at alleviating challenges associated with improper payments, specifically audit methodologies and targeting and changes to risk scores.

Project goals include developing new, sophisticated methods for audit targeting and improved profilepayment error correlations, specifically focused on Medicare Part C, the program under which MAOs provide health care services to beneficiaries. ORNL conducted RADV analyses against RAPS and EDS data as well as a hospice landscape analysis per a January 2015 dataset that included Medicare beneficiaries who were in hospice in 2017 and 2018. Ongoing work under this project also involves development of predictive models for RADV investigations and hospice landscape.

Specific tasks under this effort include:

- Discovery of additional diagnosis: diagnoses not submitted for payment 
- Discovery of beneficiary profile patterns: beneficiary profiles with unexpected payment error correlation

- Discovery of deleted diagnosis: diagnoses originally submitted, but deleted within the submission window

- Discovery of chart review landscape: diagnoses submitted or deleted as part of a chart review

- Landscape of hospice utilization: understanding and investigation of utilization patterns of hospice services

To conduct the exploratory work, ORNL received RAPS and EDS data as well as RADV data. Other data inputs include supplemental MAO, ENCLSAS (Encounter Data Version of the RAPS Diagnosis Data), Monthly Membership Report, and Hospice datasets.

\section{DATA MANAGEMENT FRAMEWORK}

As specified in the Data Management Plan, ORNL receives CMS data as read-only, time-stamped data files accompanied by a metadata companion file. Files are fixed-width, delimited data (i.e., text) files. Data is transferred to ORNL via secure file transfer protocol (SFTP) and, on request, results can be transferred back to CMS via SFTP. All data ingress is approved by the ORNL Knowledge Discovery Infrastructure (KDI) team.

All received data is parsed by data engineering processes, producing Apache Parquet files, which are made available to authorized analysts for research in the ORNL Data Lake. The data engineering parsing scripts (i.e., Jupyter notebooks) are stored in an internal, secure, password-protected GitLab repository, accessible only to ORNL project engineers and data scientists. ORNL's versioning scheme tracks all data updates as received from all sources. The Jupyter notebooks specify a data product and version as part of the analysis.

KDI utilizes a combination of backup tools to ensure the availability of all data at all times. Commvault Hyperscale follows ORNL Enterprise standards and Rsync for high-performance computing systems. KDI utilizes the Commvault Image and Commvault Client backup method only in the CMS tenant. Backups of CMS may be run on the following schedule:

- Daily: Backups run on a daily schedule are retained for a period of 7 days.

- Weekly: Backups run on a scheduled day of the week are retained for a month.

- Monthly: The last scheduled weekly backup for the month is saved as the monthly backup and retained for 3 months.

\section{LITERATURE SEARCH}

In addition to analyses performed on the January 2015 dataset, ORNL conducted a literature search on hospice utilization and fraud studies, with a goal of comparing our narrow findings with other hospice landscape studies. In the area of hospice utilization, the team reviewed patient demographics, home-based vs. institutional (i.e., nursing home) hospice use, and ICU admissions compared to hospice admissions over time. In the area of fraud studies, the team reviewed topics including insufficient care, inappropriate 
billing, false claims, and general noncompliance. We also reviewed studies of for-profit vs. nonprofit hospice providers and the impact of Operation Restore Trust, a 2-year HHS study that examined how federal-state partnerships could reduce WFA in home health care, nursing homes, and durable medical equipment.

\subsection{HOSPICE CARE DEFINITION AND BRIEF HISTORY}

Hospice care became popularized in the United States in the 1970s, after nearly two decades of influence from Cicely Saunders, a nurse from Great Britain who coined the term hospice and used it to refer to an interdisciplinary treatment program focused on providing comfort, rather than a cure, for dying patients. Elisabeth Kübler-Ross, a psychologist and author of On Death and Dying, was another advocate for end-of-life support who played a crucial role in initiating hospice care as a medical discipline in the United States. Hospice care initially was a nonprofit industry. Hugh Westbrook opened the first for-profit hospice agency in the 1980s after assisting with legislation that included hospice services as a Medicare benefit. The introduction of for-profit hospice care has resulted over time in questions regarding impact on quality of care and support for patients and their families.

As of 2021, hospice coverage is available to Medicare beneficiaries with physician certification of terminal illness with life expectancy of 6 months of less. Upon admission to hospice, patients waive their rights to curative care in favor of palliative care. Should the patient outlive their prognosis, periodic reassessments of their condition will occur, but the individual will remain on hospice so long as their life expectancy is evaluated at 6 months or less, unless the patient elects to return to curative care.

PYA Analytics reports in a December 2021 whitepaper that there are four distinct levels of hospice care: Routine Home Care (RHC), Continuous Home Care (CHC), Respite Care, and General Inpatient Care (GIP). RHC is the most common and refers to care that is provided at home or at the beneficiary's place of residence. $\mathrm{CHC}$ is also delivered at the beneficiary's residence but is specifically reserved for crisis situations in which consistent and quickly available care is necessary to alleviate discomfort from distressing symptoms. Respite care is short-term care provided at an inpatient facility or nursing home that can be used to allow the primary caregiver to rest. GIP is provided at an inpatient facility but like CHC, is also reserved for crisis situations. As of 2021, the daily rates at which these levels of care are provided (i.e., daily rates at which CMS reimburses a facility or provider) are as follows: $\$ 195.61$ (RHC, for the first 60 days), $\$ 154.42$ (RHC, for $61+$ days), $\$ 452.08$ (Respite), $\$ 1,025.23$ (GIP), and \$1,404.44 (CHC). By far, RHC is the least expensive, with GIP and CHC being the most expensive. Rates are dependent on the intensity of care that the patient is receiving. PYA also reports that as of 2019, the overwhelming majority of hospice days are spent in RHC (>98\%), followed by GIP (1.2\%), Respite $(0.3 \%)$, and $\mathrm{CHC}(0.2 \%)$.

\subsection{IDENTIFYING FRAUD SCHEMES IN HOSPICE CARE}

For this review, fraud is defined as any intentional error that results in overpayment by CMS to hospice providers. Audit reports released from November 2020 through May 2021 by the Office of the Inspector General (OIG) on several hospice agencies outline the severity of fraud in the hospice industry, with providers collecting tens of millions of dollars in Medicare overpayments. Most commonly, these overpayments result from inappropriate billing. Audit findings from Hospice Compassus, Inc. (Payson, AZ); Hospice Compassus, Inc. (Tullahoma, TN); Tidewell Hospice (Sarasota, FL); Alive Hospice (Nashville, TN); and Suncoast Hospice (Florida) highlight common fraud issues. 
Except for Hospice Compassus, Inc., of Tullahoma, TN, these agencies each had claims - as few as four and as many as 20 - that were billing for a higher level of care than medically necessary based on review of 100 random claims. In each of these cases, claims were filed for a higher level of care, such as general inpatient or continuous home care, when the patient's symptoms could have been managed for a lower per diem cost with routine home care.

Similarly, except for Alive Hospice, these agencies all had some form of inconsistency between the services billed and services provided (Suncoast) or documented (Hospice Compassus, Inc., both locations). In the case of Tidewell, the audit uncovered four claims for services that were not eligible for reimbursement. Two (from Suncoast) of the 100 sample claims were found to involve inaccurate nursing visit hours, including claims that followed the death of the beneficiary for one of the claims. Hospice Compassus, Inc., had a combination of 19 hospice claims between the two locations for services that were not documented in the patient's medical record.

All these agencies delivered services to beneficiaries that were not supported by their diagnoses. In a random sample of 100 claims, at a minimum, Tidewell had 9 patients on services and, at a maximum, Suncoast had 30 patients on services, whose medical records did not contain supporting evidence of a terminal prognosis. Other, less common, issues involved patients being onboarded and receiving hospice care before their documentation was submitted. In this single study, overpayments to the hospice providers totaled hundreds of millions of dollars.

\subsection{FRAUD PREVENTION MEASURES}

CMS' ability to detect fraud relies on audits that utilize records provided by hospice providers. The OIG currently recommends that CMS instruct auditors to look closely at hospice agencies that do not provide all four levels of care (i.e., home-based hospice, continuous hospice, inpatient hospice, respite care), as this may result in insufficient care for patients, as well as those with repeated deficiencies. Hospice agencies have faced criminal investigation and fines under the False Claims Act. CMS does not currently have a mechanism for closely monitoring hospice agencies, but if an agency is found to have severe deficiencies or vulnerabilities, it is removed as a Medicare-approved hospice provider.

\subsection{IMPACT OF HOSPICE FRAUD BEYOND MEDICARE OVERPAYMENTS}

While preventing fraud within hospice care is an important factor for relieving the financial burden on CMS, concern is arising that current preventative measures are contributing to underutilization of hospice. Particularly in long-term care facilities such as nursing homes, hospice utilization is low, likely due to colluding factors of eligibility restrictions, available types of care, and financial incentives. Because of the potential legal and financial consequences surrounding hospice care fraud, physicians are increasingly hesitant to refer individuals to hospice unless it is clear that they are actively dying and will not outlive their prognosis. There are known cases of hospice agencies have paid recruiters to seek out patients for their service who are not terminally ill and, thus, ineligible for hospice. Because hospice agencies are paid a per diem rate for each of their beneficiaries, there is an incentive for providers to onboard patients with simple needs that do not require a high level of care from their staff or patients with diagnoses that will allow them to remain on service for an extended period. Furthermore, it is unclear that patients fully understand that they waive their right to curative care at hospice facilities. As such, in these situations, hospice may shorten the lifespan of those beneficiaries. 
A small sample of audits of hospice agencies across the United States showed that each one had at least a few occurrences of the following: ineligible patients on hospice service, inappropriate billing of a higher level of care than necessary, and billing for services either not provided or not properly documented. In each of these cases, these agencies were subject to millions of dollars in overpayments. It should be noted that ORNL data analyses cannot determine whether or not any of the infractions were intentional; any or all could simply result from insufficient documentation. The OIG recommends tightening retrospective hospice surveys to focus on agencies that provide limited patient care services, have noticeably lower physician involvement, and/or have repeated deficiencies. The OIG also recommends that CMS develop alternative courses of corrective action for hospices that do not involve removing their Medicareapproved agency status, which would result in a severe drop in enrollment of eligible patients into hospice. Lastly, it is necessary to consider the impact of heavy penalties, both financial and legal, on hospice referrals, as too stringent enforcement may discourage physicians from referring eligible patients for fear they may outlive their prognosis or not experience a decline in condition as quickly or as linearly as expected.

\section{HOSPICE LANDSCAPE ANALYSES}

ORNL conducted a landscape study to understand the state of hospice care, looking at the data related to age, sex, geographic location, and diagnosis distributions. This section provides a high-level overview of our demographic findings as well as additional information on diagnoses after grouping them into broader categories. This section also includes a first look at length-of-stay calculations and their correlations to principal diagnoses, and 1 beneficiary statistics regarding payment amounts, number of hospice stays, and number of claims per beneficiary.

Data inputs included the Claim (CLM), Claim Line (CLMLN), Claim Diagnosis (CLMDG), and Inpatient (INPNT) data tables. In total, we were presented with $271.5 \mathrm{~GB}$ of cleaned and processed data that is ready for analysis. The data represents 4.1 million beneficiaries and 5.7 billion records. The claim dates for the dataset were January 2015-June 2019. Importantly, we note that while in total there are 4.1 million beneficiaries present in this data, this analysis is limited to the 1.6 million beneficiaries that are present with a hospice indicator. The remaining $2.5 \mathrm{M}$ individuals are not current hospice beneficiaries, and the data for these represents historical claim data prior to their hospice admission 2-3 years later.

The dataset contained 1.6 million unique hospice beneficiary records. Forty-two percent of hospice patients were male, and $52 \%$ were female (Figure 1). 


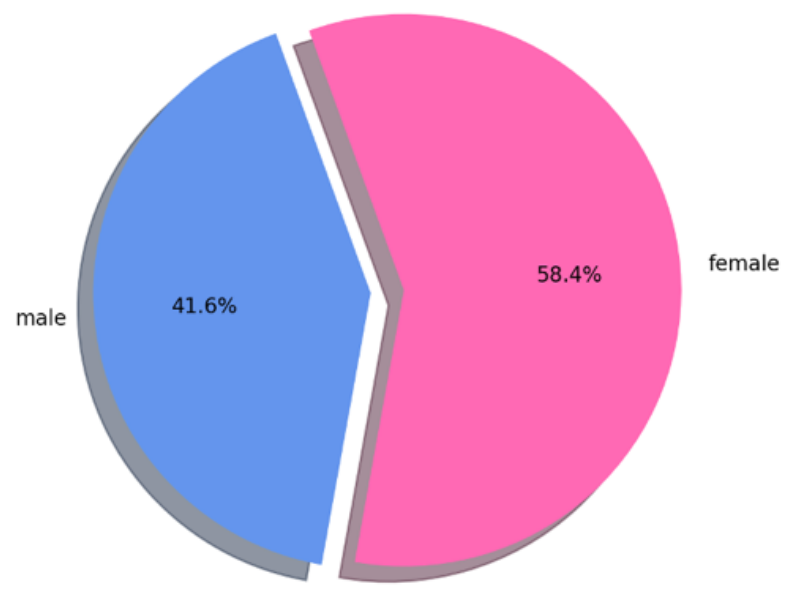

Figure 1. Gender distribution of hospice patients, January 2015-June 2019.

In this analysis, hospice usage was normalized by the number of Medicare beneficiaries in each state. The team found that minimum usage of hospice by Medicare beneficiaries for Alaska, North Dakota, and Wyoming, with high levels of usage in Alabama, Ohio, and Utah (Figure 2). Future analysis will examine rural vs. urban usage of hospice.

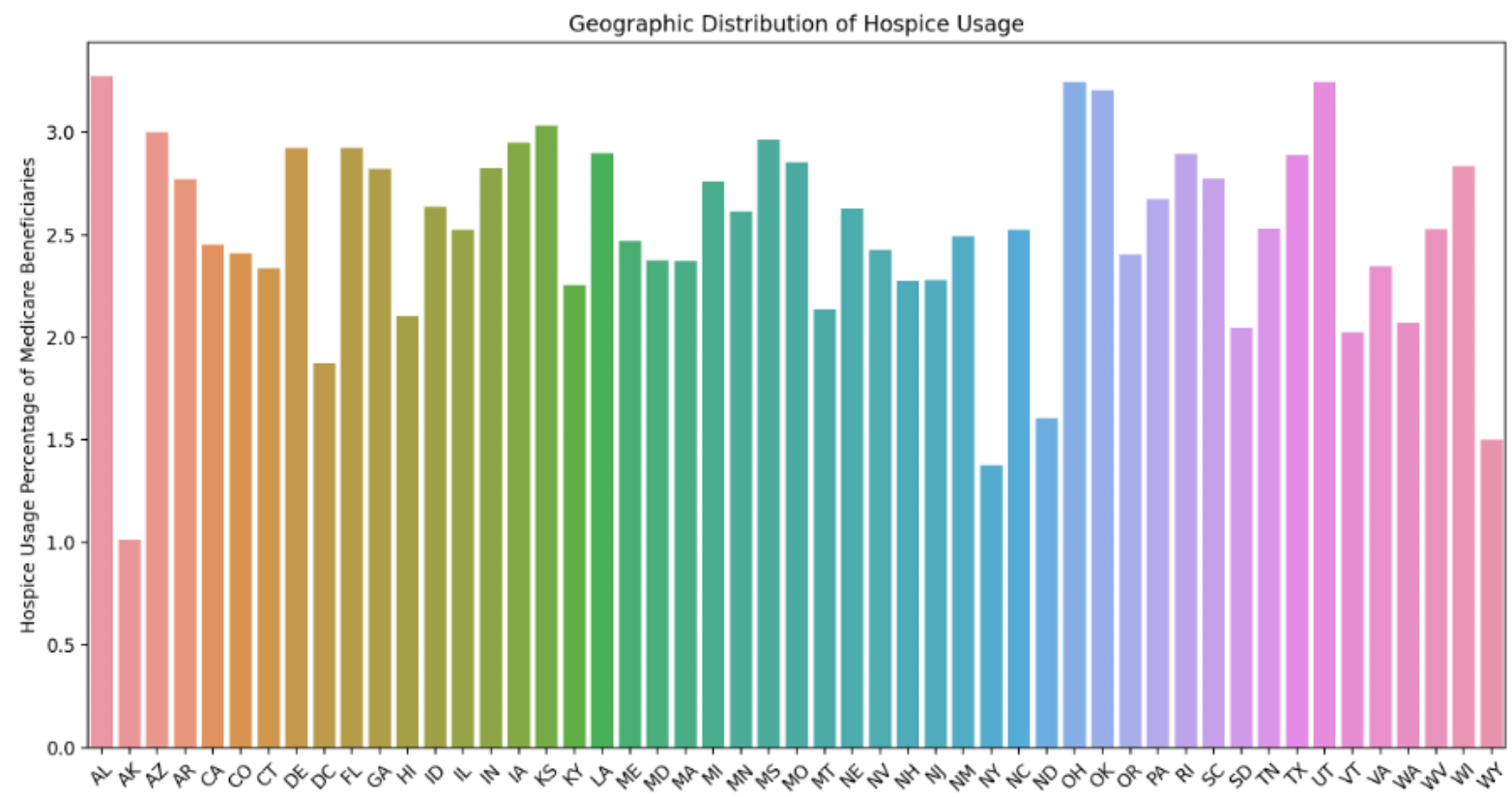

Figure 2. Geographical distribution of hospice patients, January 2015-June 2019. 
ORNL/SPR-2021/2271

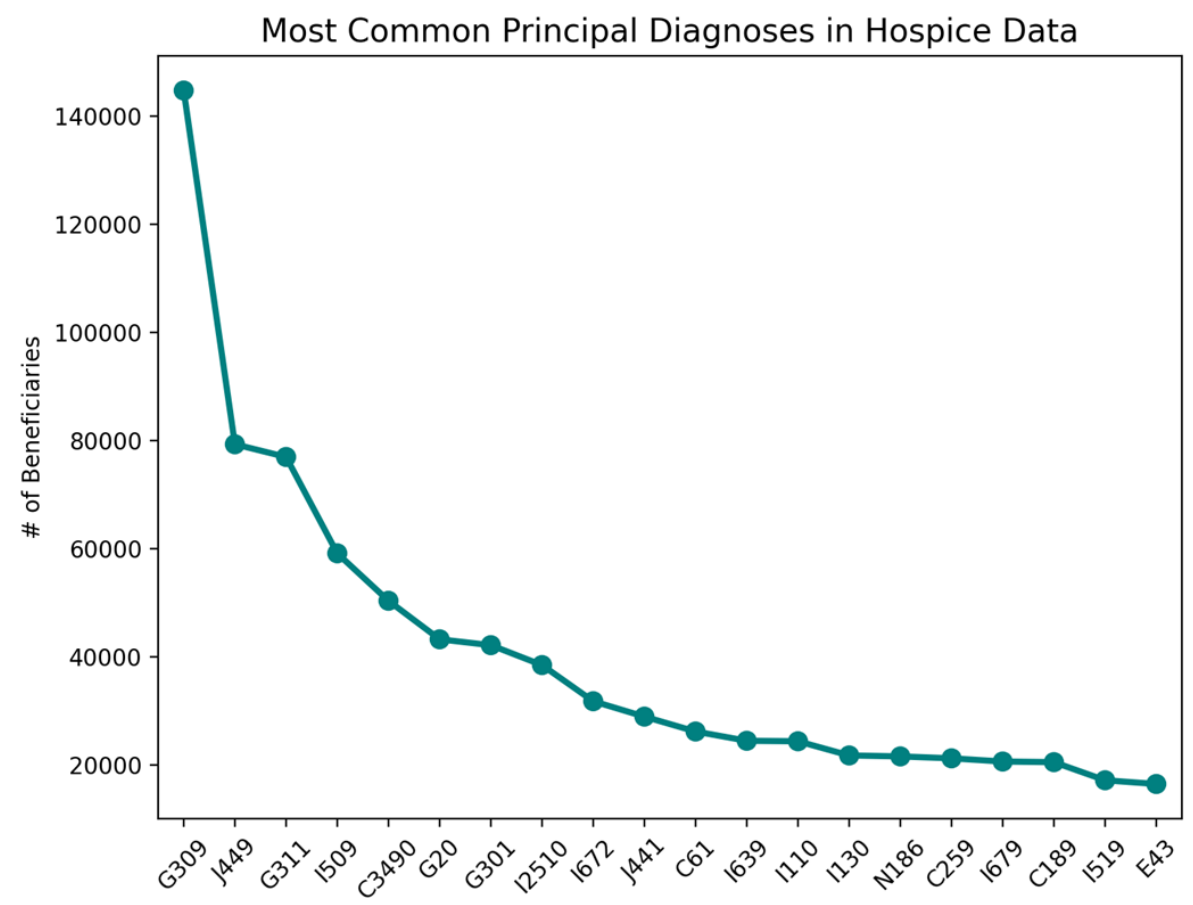

Figure 3. Diagnosis distribution of hospice patients, January 2015-June 2019.

The team also analyzed the top principal diagnosis codes found for hospice patients (Figure 3). The most prevalent diseases, in descending order by number of beneficiaries with these diagnosis codes, were found to be:

1. Alzheimer's Disease

2. Chronic Obstructive Pulmonary Disease (COPD)

3. Senile Degeneration of Brain

4. Heart Failure

5. Malignant Neoplasm of Bronchus/Lung

6. Parkinson's Disease

7. Late Onset Alzheimer's Disease

8. Artherosclerotic Heart Disease w/o Angina

9. Cerebral Artherosclerosis

10. COPD w/ Acute Exacerbation

The team then rolled the above ICD-10 codes into broader categories known as major diagnosis codes (MDCs) (Figure 4). We found that the most common MDCs of principal diagnoses are:

1. Circulatory System Diseases

2. Neoplasms

3. Nervous System Diseases

4. Respiratory System Diseases

5. Endocrine, Nutritional, \& Metabolic Diseases

6. Genitourinary

7. Digestive Diseases 
ORNL/SPR-2021/2271

8. Infectious and Parasitic Diseases

9. Unclassified Abnormal Findings (i.e., diagnoses and conditions not properly documented)

10. External Causes

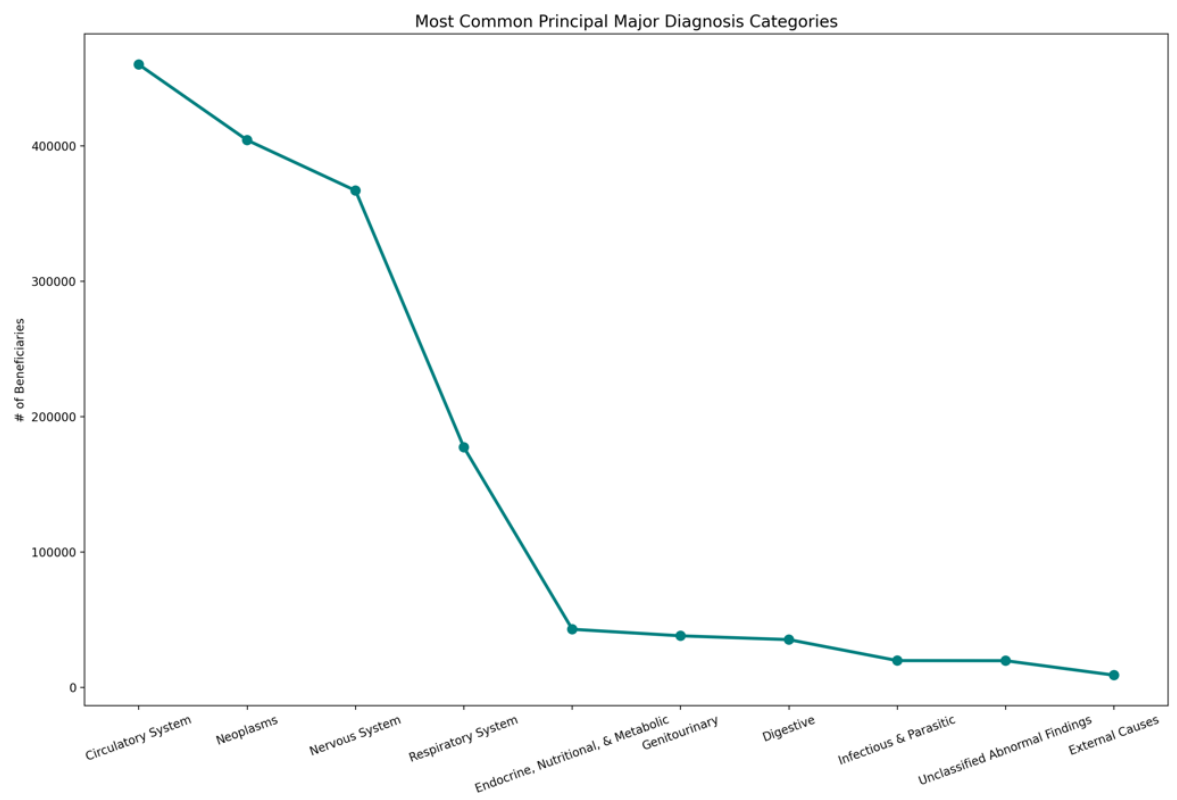

Figure 4. MDC distribution of hospice patients, January 2015-June 2019.

Beneficiary statistics were calculated to expand our understanding of the data. The team reported both average and median due to the median's stronger resistance to outliers in the data. On average, the dataset included $119.6 \pm 213.4$ claims per beneficiary, with a median of 39 claims. This large variability in number of beneficiary claims is logical as hospice is billed on a per diem basis and the data contains a sizable range of length of hospice stays.

The dataset also shows that the average claim payment amount across beneficiaries was $\$ 3,406.78 \pm$ $\$ 1,871.63$, with a median of $\$ 3,833.12$. We would similarly expect a large variation in claim payment amounts because the per diem payrate is based on level of care, with at-home care being much less expensive than inpatient care. The team also found that the average total cost of a hospice beneficiary during their length of stay was $\$ 522,484 \pm \$ 962,052$, with a median of $\$ 151,149$. Again, this metric varies widely with level of care so, here, the median may be a better estimate of hospice costs.

The team performed a rudimentary analysis of the length of stay of hospice beneficiaries. First, we considered their total time on hospice services to be the difference in months between their first claim data and their most recent claim date. From this calculation, we found that the average length of stay is $4.5 \pm 8.5$ months, with a median of 0.67 months. We also explored the number of hospice admissions. We considered a single hospice stay as a group of claim dates no further than 30 days apart, and where two claim dates were more than 30 days apart, they were counted as two separate hospice stays. With these criteria, the team found that, on average, beneficiaries were admitted to hospice $4.1 \pm 6.2$ times, with a median of 1 time. Finally, we computed their number of days on hospice as the sum of the days during each hospice stay. We find that on average, the length of stay was $18 \pm 25$ days, with a median of 8 days. This is much lower than previously published data, and we are modifying our length of stay calculations as follows: 


\begin{tabular}{|c|c|c|}
\hline CLM_FROM_DT & CLM_THRU_DT \\
\hline $01 / 01 / 2015$ & $01 / 01 / 2015$ & \\
\hline $01 / 02 / 2015$ & $01 / 04 / 2015$ & \\
\hline $01 / 05 / 2015$ & $01 / 05 / 2015$ & \\
\hline $01 / 06 / 2015$ & $01 / 07 / 2015$ & 1 \\
\hline
\end{tabular}

where we will sum the differences across the claim-from and claim-through dates. As it stands now, however, roughly $46 \%$ have a length of stay of less than 5 days; $8.2 \%, 5-10$ days; $26.0 \%, 10-30$ days; $17.1 \%, 30-90$ days; $2.3 \%, 90-180$ days; $0.07 \%, 180-365$ days; and $0.002 \%$, greater than 365 days.

As part of the current analysis, the team investigated how length of stay might correlate to diagnoses correlation (Figure 5). In each category of length of stay, Alzheimer's disease or some variation of it dominates all other disease codes. However, the exceptionally short length of stay bins do contain beneficiaries with cancerous diseases. Based on this information, the team will investigate disease pairings, as Alzheimer's disease, dementia, and others likely contribute to, but are not the sole reason for, an individual's admission to hospice.
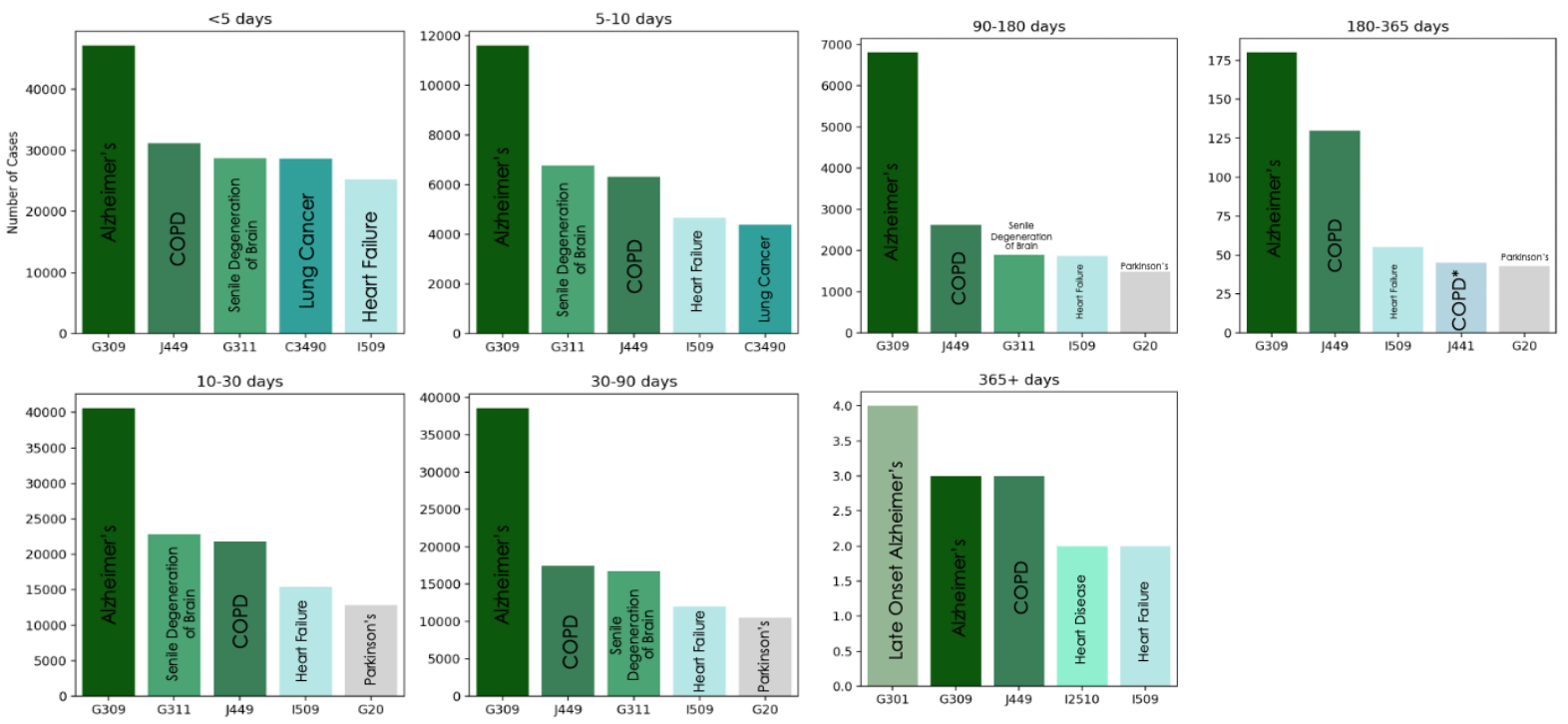

Figure 5. Correlation of length of stay to diagnosis codes. 

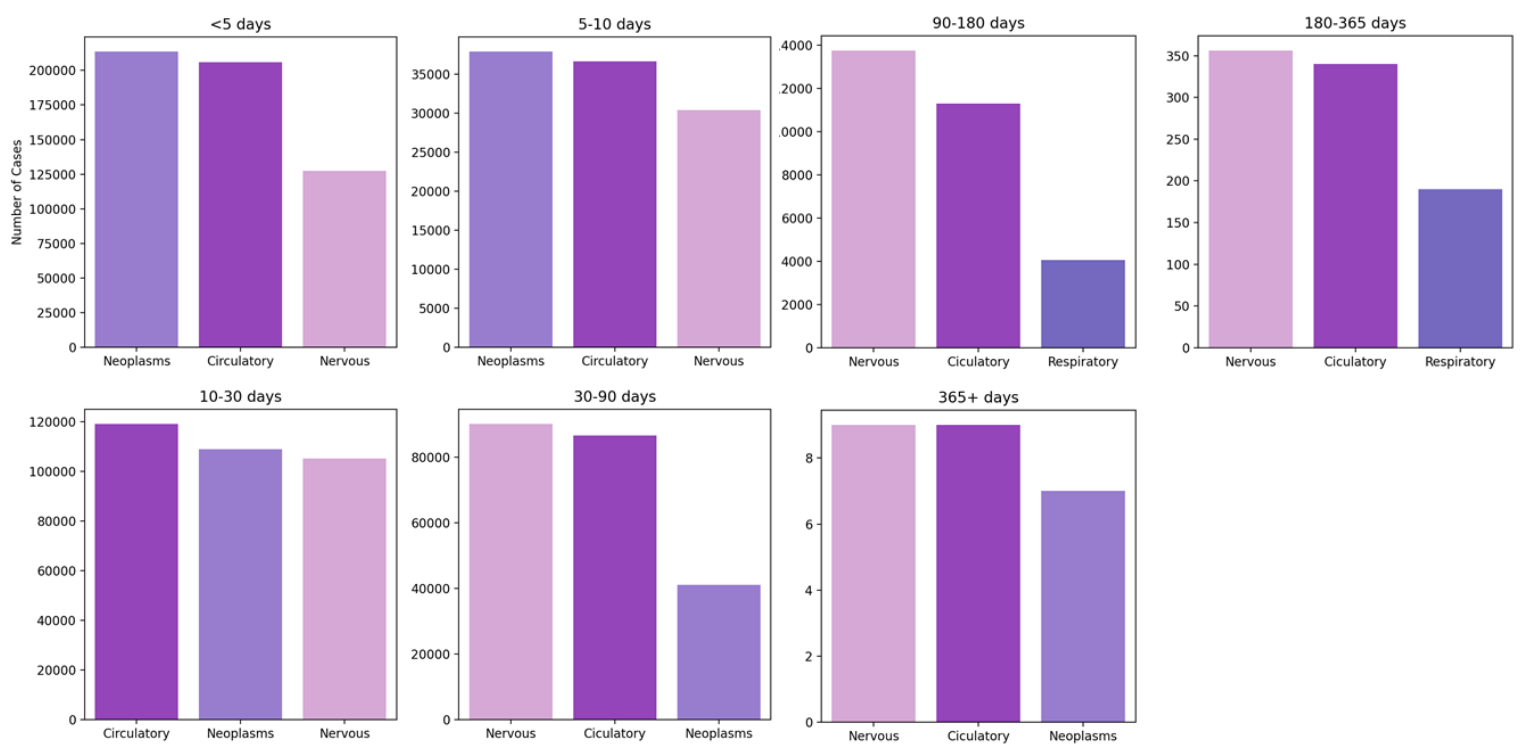

Figure 6. Correlation of length of stay to MDC.

The team also investigated the correlation between MDC and length of stay (Figure 6). Interestingly, rolling diagnosis codes into MDCs revealed that for short length of stays, cancer and circulatory diseases are predominate over nervous system diseases, whereas for longer length of stays, the opposite is found.

\section{FUTURE WORK}

This report has provided findings from our initial landscape analysis of hospice care. Though we have learned worthwhile information from the initial dataset, we have also identified several other notable threads that will expand our understanding of hospice. First, concerning diagnoses of hospice patients, the team will extend analyses to include the secondary and tertiary diagnoses as well as the principal diagnosis reported for each beneficiary. While Alzheimer's disease and other dementia-type diseases were found to be the principal diagnoses of hospice patients in this study, we hypothesize that most have other conditions that contributed more strongly to their terminal diagnoses. In future analyses, we will investigate diagnosis pairs to determine which secondary and tertiary diagnoses Alzheimer's and other dementia-type disease diagnoses were commonly paired with. The team also will examine diagnosis pairs by hospice patient age. We expect to see more dementia-type diseases in the older population, but it would be illuminating to discover the common diagnosis pairings across age groups.

Second, from the initial landscape analysis, we noted that, based on the geographic distribution, in general more rural locations exhibit less hospice usage overall. This warrants at least a superficial investigation of rural vs. urban usage of hospice care, and the team recommends also studying rural vs. urban length of stay on service and survivability.

Third, the team will explore payment amounts as they relate to the four levels of hospice care. This is critical for tracking "where the money goes," to see roughly how much is being spent on each level of care.

Each of these threads will contribute to our predictive model of hospice length of stay and understanding what is driving the large variability that CMS has observed. Certain demographics, diagnoses, or care types may be essential to generating a reliable model, but each must first be investigated in a stand-alone 
analysis to develop a broad understanding of the importance of each. After this is understood, their relationships to each other can be investigated.

\section{REFERENCES}

Arnold, J., Srinivas, N., Begoli, E., Goethert, I., Linares, F., Redmon, D., Cohen, J., and Schmidt, E. "Summary of Results to Date of RADV Data Analysis." Unpublished ORNL Sponsor Report, April 2021.

Barger, J. "Life, Death, and Medicare Fraud: The Corruption of Hospice and What the Private Public Partnership under the Federal False Claims Act Is Doing about It." American Criminal Law Review 53, no. 1 (March 16, 2016). https://papers.ssrn.com/sol3/papers.cfm?abstract id=2747543.

Centers for Medicare and Medicaid Services. "Hospice." https://www.cms.gov/Medicare/Medicare-Feefor-Service-Payment/Hospice. Page last modified August 17, 2021.

Centers for Medicare and Medicaid Services. "Center for Program Integrity: Protecting Medicare and Medicaid Programs from Fraud, Waste, and Abuse," https://www.cms.gov/AboutCMS/Components/CPI. Page last modified June 24, 2021.

Centers for Medicare and Medicaid Services. "Medicare Beneficiaries at a Glance," https://www.cms.gov/Research-Statistics-Data-and-Systems/Statistics-Trends-andReports/Beneficiary-Snapshot/Bene Snapshot. Page last modified December 11, 2020.

Centers for Medicare and Medicaid Services. "CMS' Program History," https://www.cms.gov/aboutcms/agency-information/history. Page last modified January 13, 2020.

Fine, P. G. "Hospice Underutilization in the U.S.: The Misalignment of Regulatory Policy and Clinical Reality.” Journal of Pain and Symptom Management 56, no. 5 (November 2018): 808-815. https://pubmed.ncbi.nlm.nih.gov/30142388/.

Hoffmann, D. E., and Tarzian, A. J. "Dying in America: An Examination of Policies that Deter Adequate End-of-Life Care in Nursing Homes.” The Journal of Law, Medicine \& Ethics (June 1, 2005). https://journals.sagepub.com/doi/abs/10.1111/j.1748-720X.2005.tb00495.x.

National Hospice and Palliative Care Organization. NHPCO Facts and Figures, 2018 edition. Alexandria, VA: NHPCO (2018, revised July 2, 2019). https://39k5cmla9u1968hg74aj3x51-wpengine.netdnassl.com/wp-content/uploads/2019/07/2018 NHPCO Facts Figures.pdf.

PYA Analytics. Hospice Themes: Hospice Services Key Trends and Findings. Prepared for Oak Ridge National Laboratory. December 2021.

Redmon, D. “CMS Data Management Plan.” Unpublished ORNL Sponsor Report, September 2021.

US Department of Health and Human Services, Office of the Inspector General. Medicare Hospice Provider Compliance Audit: Alive Hospice, Inc. Report no. A-09-18-03016 (May 2021). https://oig.hhs.gov/oas/reports/region9/91803016.pdf.

US Department of Health and Human Services, Office of the Inspector General. Medicare Hospice Provider Compliance Audit: Hospice Compassus, Inc., of Payson, Arizona. Report no. A-02-1601023 (November 2020). https://oig.hhs.gov/oas/reports/region2/21601023.pdf. 
ORNL/SPR-2021/2271

US Department of Health and Human Services, Office of the Inspector General. Medicare Hospice Provider Compliance Audit: Hospice Compassus, Inc., of Tullahoma, Tennessee. Report no. A-0216-01024 (December 2020). https://oig.hhs.gov/oas/reports/region2/21601024.pdf.

US Department of Health and Human Services, Office of the Inspector General. Medicare Hospice Provider Compliance Audit: Suncoast Hospice. Report no. A-02-18-01001 (May 2021). https://www.oig.hhs.gov/oas/reports/region2/21801001.pdf.

US Department of Health and Human Services, Office of the Inspector General. Medicare Hospice Provider Compliance Audit: Tidewell Hospice, Inc. Report no. A-02-18-01024 (February 2021). https://oig.hhs.gov/oas/reports/region2/21801024.pdf.

US Department of Health and Human Services, Office of the Inspector General. Safeguards Must Be Strengthened to Protect Medicare Hospice Beneficiaries from Harm. Report no. OEI-02-17-00021 (July 2019). https://oig.hhs.gov/oei/reports/oei-02-17-00021.asp.

US Department of Health and Human Services, Office of the Inspector General. Vulnerabilities in the Medicare Hospice Program Affect Quality Care and Program Integrity: An OIG Portfolio. Report no. OEI-02-16-00570 (July 2018). https://oig.hhs.gov/oei/reports/oei-02-16-00570.pdf.

US Government Accountability Office. Medicare Hospice Care: Opportunities Exist to Strengthen CMS Oversight of Hospice Providers. Report no. GAO-20-10 (October 2019).

https://www.gao.gov/products/gao-20-10. 